\section{A different perspective to define language learning strategies}

Di Carlo, Sergio

School of Languages, National University of Córdoba, Argentina (contact@sergiodicarlo.com)

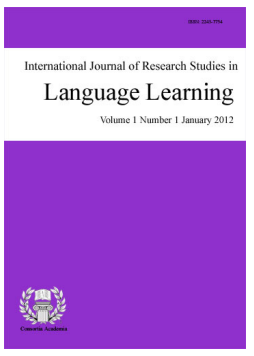

ISSN: $2243-7754$

Received: 27 July 2016

Revised: 21 August 2016 DOI: $10.5861 /$ ijrsll.2016.1594
Accepted: 1 September 2016

\title{
Abstract
}

Most authors agree that learning a language can be optimized through the use of strategies. However, there is no agreement on what exactly strategies are and what characteristics they have. The lack of clarity or the generalization in many of the definitions cause some problems in the empirical field and the measurements performed tend to present weak psychometric properties. This article presents a critical analysis of different definitions and a search for patterns and etymological tracking, in order to specify the attributes underlying the concept of language learning strategy. The new proposed definition establishes a clear difference between what is strategic and what is not, based on the notion of efficacy and efficiency. Furthermore, secondary inherent characteristics of strategies are examined. The article concludes with a discussion of theoretical and empirical implications and methodological suggestions.

Keywords: attributes; efficacy; efficiency; meta-analysis; second language; foreign language 


\section{A different perspective to define language learning strategies}

\section{Introduction}

Since strategies were introduced into the field of humanities, during the last 30 or 40 years, controversies have arisen. A burning issue has been the difficulty in defining strategies (Oxford, 1990; Oxford \& Cohen, 1992) and in reaching an agreement regarding this aspect. Macaro (2006) also noticed this difficulty and the lack of theoretical rigour could lead to despair of achieving an all-encompassing definition. Dörnyei (2005, p. 162) was even more drastic and stated that "learning strategies are immensely ambiguous phenomena and nothing is clear-cut about them", questioning if learning strategies really exist. This imprecision in the theory has also impacted on the psychometric properties of empirical studies, hence the importance of seeking solutions.

The two main limitations surrounding the notions of language learning strategies are: (1) there is no unified definition of strategies ${ }^{1}$, and (2) in many versions found in literature, the concept lacks precision in its characterization and tends to be so global that it turns fuzzy ${ }^{2}$, to the extent that everything could be considered as strategic. In an attempt to overcome such limitations, in this paper I present an analysis of different definitions of strategy, learning strategies and language learning strategies, with the purpose of finding patterns to define the main attributes of the concept of strategy.

\subsection{Finding patterns and clarifying issues}

Let us start with the definition proposed by Oxford (1993, p. 18), who described learning strategies as:

specific actions, behaviors, steps, or techniques that students use to improve their own progress in developing skills in a second or foreign language. These strategies can facilitate the internalization, storage, retrieval, or use of the new language (p. 18).

Dörnyei (2005) stated that, although this definition is one of the best of its kind and it seems to be logical and exhaustive, it is not clear enough on drawing a distinction between ordinary learning and what strategic learning would be; in other words, it is not explained what the characteristics are for a certain activity (technique, procedure, process, etc.) to be regarded as strategic. According to this definition, a learner could try to learn a language by reeling off isolated and random words from a dictionary, and in this case, it would be his/her strategy since this activity would help in developing his/her skills in the target language. In the same way, it could help in processing such information, although it is barely probable that performing this activity could actually help in learning the language (understanding it as a synonym for a comprehensive development of the communicative competence in the target language).

There is an approach that considers the element of consciousness as the key and defining attribute for a strategy to be considered as such. The authors supporting this idea state that 'the element of consciousness is what distinguishes strategies from those processes that are not strategic' (Cohen, 1998, p. 4) ${ }^{3}$ or, that:

If the activity is consciously chosen by learners for the purpose of regulating their own language learning it is a strategy (Griffiths, 2013, p. 15).

However, to perform a determined action consciously does not make it any special. Human beings are rational beings practically all the time, performing voluntary, conscious and deliberate actions to accomplish their goals whatsoever. In this respect, if we consider that a strategy is everything that it is performed intentionally to

\footnotetext{
${ }^{1}$ Cohen (1998) talked of 'conflicting views'.

2 Ellis (1994) pointed out the fuzziness of the concept.

${ }^{3}$ Cohen (2015) still supported this view.
} 
accomplish a goal in a person's life (regardless the real impact of such strategies), everything would be a strategy: from simple activities like opening the tap to have running water, making a phone call, tapping a key, repeating words endlessly, turning the pages on a book, to those more complex activities as writing an essay or reading literature. How could this universe of actions be operationalized? Besides, the term consciousness itself can be split up in different aspects. For example, Schmidt (1994) suggested four dimensions or aspects (intentionality, attention, awareness, and control), while Dörnyei and Scott (1997) recommended three. On the other hand, these two last authors considered that: "Consciousness has, in fact, so many different connotations that one would best avoid it altogether” (Dörnyei \& Scott, 1997, p. 184). Following this line of thought, McLaughlin pointed out:

although the terms 'conscious' and 'unconscious' have a place in our prescientific vocabulary, they have acquired too much surplus meaning and should be abandoned in favor of clearly defined empirical concepts (McLaughlin, 1990, p. 617).

Another disadvantage of considering the element of consciousness as a variable is the enormous difficulty to access (if that is even possible) the unconscious (which would be the other possible variation) by reliable empirical techniques. These are the reasons why I consider that it is not convenient to take the element of consciousness as the main attribute to define strategies, but instead to consider this element as just another secondary feature. It is worth mentioning that strategies can also be potentially conscious: 'potentially conscious plans for solving what to an individual presents itself as a problem in reaching a particular communicative goal' (Faerch \& Kasper, 1983, p. 212). So in this paper, strategies will be considered as conscious or potentially conscious processes ${ }^{4}$. Complementing what Braunstein, Pasternac, and Benedito (2002) expressed, as the term conscious refers to what we can be aware of at every single moment of our psychic activity, the potentially conscious refers to everything that is, at the moment, irreflexive, preconscious and spontaneous to us, but that it can be brought to the consciousness and recovered from the metaknowledge if there are no opposing forces. Another definition came from the Council of Europe:

A strategy is any organised, purposeful and regulated line of action chosen by an individual to carry out a task [emphasis added] which he or she sets for himself or herself or with which he or she is confronted (Council of Europe, 2002, p. 10).

The underlying broadness of this concept is its major weakness which is due to the difficulty of operationalizing it. Moreover, according to this definition, the organization, intention and regulation would be the attributes to determine that a said action is a strategy. Again, if we take as an example the learner and his/her repetitions by heart, we would see that this activity complies with the requirements, but the question is whether the learner will achieve his/her objectives and to what extent. What I consider necessary to stress in this definition is the presence of a task, which implies goals and objectives ${ }^{5}$ to be fulfilled, since they are the rationale underlying the strategies. In other words, the existence of an objective (or goal) and the actions taken to achieve that objective is an essential condition for strategies to exist, but it is not enough. The fact that strategies are goal-oriented is one of the characteristics that most authors agree on (Chamot, 2001; Cohen, 1998; Oxford, 2013; Griffiths, 2013; Macaro, 2006).

Another definition for learning strategies is that one from Díaz Barriga and Hernández Rojas, who considered that learning strategies are procedures (steps, operations or abilities) that a learner applies intentionally, consciously and controlled as flexible instruments to learn meaningfully and solve problems (Díaz Barriga \& Hernández Rojas, 2002, p. 234). To this respect, the theory of meaningful learning adapts well to building up knowledge, but being competent in a language also implies the development of skills that do not necessarily adjust to the postulates of that theory. Skills are effective ways of acting that can be developed and improved (Ledesma, 1979). They involve contents of different types, such as, perceptive, conceptual, cognitive,

\footnotetext{
4 This criterion is also supported by Fernández (2004), Oxford (1990), Díaz Barriga and Hernández Rojas (2002), O’Malley and Chamot (1990), among others.

5 The goals represent the more immediate and concrete purposes, while the objectives are projected to be fulfilled in a longer term and with a broader degree of inclusion.
} 
muscle, motor contents, etc. and they are generated from a multiplicity of events and molecular actions (even the instinctive, automatic and out of reflexive consciousness) that are embedded in the activities (Villanueva, 2008). Skills cannot be developed by reading about it or by listening to explanations, but through practice, in a continuum of implementation, correction and improvement, although this does not mean that it cannot be related to theoretical and declarative knowledge. The most important characteristic in this definition is that strategies can be used to solve problems; nevertheless, this is not new since Bialystok $(1984,1990)$ had already pointed out that one of the main purposes of strategies was to overcome problems. I consider that strategies can also be used to cope with difficulties, increase and exploit strengths and overcome weaknesses.

Nisbet and Shucksmith (1986) pointed out that a strategy consists of selecting the right skills in each situation and applying them in a proper way. For them, a strategy is mainly understood as an intellectual capacity to select and apply the actions that better suit a given situation. This definition adapts to strategic thinking better than to strategies themselves, although I consider the attribute appropriateness as the most important concept to take into account.

A classic definition used in most researches dealing with the frequency of use of language learning strategies (LLS) is the one proposed by Oxford:

specific actions [emphasis added] taken by the learner to make learning easier, faster, more enjoyable, more self-directed, more effective [emphasis added], and more transferable to new situations (Oxford, 1990, p. 8).

Let us consider some of the key points in this definition. First, what are the attributes of strategies? According to the author, the answer would be: an action that contributes to make learning easy, quick, self-directed, effective and transferable. Now, is it possible to operationalize such diversity of properties or attributes? If an action contributes in making learning a quicker, more self-directed, more effective and more transferable process, but it cannot make it easier, is this action a strategy? What does effective learning involve? Are cognitive procedures actions? All these are some of the questions that could be brought up and that provoke insecurities regarding the concept defined by Oxford (1990). Nevertheless, I take actions and effective as important terms to specify and elucidate. Authors like Rubin (1975), Wenden (1991), Reid (1998), Larsen-Freeman (2001) and Griffiths (2013) determined that the LLS are activities or actions and thus they are typically expressed by verbs ${ }^{6}$.

Ferreras Remesal (2008) stated that learning strategies are cognitive, affective and motor procedures that students use in a conscious and reflective way, and that are directed to effectively achieve a goal or specific objective of learning. In the first place, I pick out from here the fact that strategies do not only refer to cognitive procedures, but also to affective and motor procedures. And this definition highlights the concept of effectiveness. It is important to put emphasis on the attribute of effectiveness when referring to meeting objectives in a strategy; however, to focus only on this achievement is not enough. Let us illustrate the reasons with the following example. If I want to learn Spanish verbs and to do it I learn by heart all verbs and their conjugations, it is possible that I fully achieve my objective but, at what cost? how much time and effort would it take? With this simple example, we can realize that there is another attribute that is essential to bring into consideration.

Up to here in this revision, it is possible to point out the most relevant characteristics found in the concept of learning strategy by answering these questions:

$>\quad$ What are learning strategies? They are plans, lines of action, concrete actions, mental operations, mechanisms, techniques, and cognitive, affective or motor procedures.

$>$ How are the learning strategies carried out? In a conscious or potentially conscious, regulated and

\footnotetext{
${ }^{6}$ This also helps to distinguish strategies from learning styles, which are related to the inner characteristics of learners and are represented by
} adjectives and nouns. 
intentional way.

$>\quad$ What is the aim of learning strategies? They are carried out to solve problems, to acquire meaningful knowledge, to fulfill tasks in a proper way, to efficiently achieve goals and objectives.

\subsection{The key attributes}

The attributes which will define the concept of strategy and will make it operationalizable remain to be determined, so I suggest looking up the essence of the term in its etymological origin and its use. The etymon of this word comes from the Indo-European *ster-, which means extending or expanding (Pastor \& Roberts 1996). This root plus an infix results in *str-to- which constitutes the Greek base form ó $\sigma \tau \rho \alpha \tau$ ó $\varsigma-0 \tilde{v}$, which means army. If the verb ó $\gamma \omega$ (leading or conducting) is added to this Greek noun, the result is the verb $\sigma \tau \rho \alpha \tau \varepsilon \gamma \varepsilon \dot{\varepsilon} \omega$, which means guiding, leading or commanding an army. In turn, this originates the final word $\dot{\eta} \sigma \tau \rho \alpha \tau \varepsilon \gamma i \alpha-\alpha \varsigma$ (strategy), understood as the capacity of command or leadership of an army. Since it is a term from the military field, let us analyze it from that perspective. When reviewing military operations in times of Ancient Greece and today, we found that there were two basic parameters at stake. First, the objectives: to defend a territory, stop the enemy's advance, seize a position, cause a larger number of casualties, eliminate or protect an individual, etc. Second, the available resources: soldiers, weapons, ammunition, vehicles, supplies, time, money, etc. Therefore, a strategy is a course of action which meets to the greatest extent possible the set objectives and goals. Not in any way but in a manner which involves the lower number of resources.

The concept of strategy, without its war connotation, has become a highly influential factor in education, acquiring a new meaning and turning into learning strategies. However, the essence underlying its original conception remains: effectiveness and efficiency. On the one hand, I define efficacy or effectiveness $(\varepsilon)$ as the degree to which goals and objectives are positively achieved. For example, if I intend to study a whole book, but I only manage to study half of it, I have attained $50 \%$ of my objective. In this case whatever the procedure followed, it has not been effective. On the other hand, efficiency $(\eta)$ refers to an amount of used resources which are required for any cognitive activity. In addition to what the Council of Europe (2002) stated, these resources include mental energy, mental and cognitive processes, forms of behavior and action, not only psychological (emotions, volitions, attitudes, etc.) but also social ones (experiences and social contact, etc.), material elements, time, economic resources, as well as the complete series of specific abilities an individual uses as a social agent. Therefore, any activity will be considered strategic if it is optimal in terms of effectiveness and efficiency as regards the set goals and objectives. These two attributes ( $\eta$ and $\varepsilon$ ) will be crucial to label an action as a strategy.

According to all the definitions here presented and the subsequent considerations, I can present the following proposal which contemplates the underlying features and properties of this analysis: language learning strategies are actions that an individual executes in a conscious or potentially conscious, relatively controlled and intentional way in order to achieve the goals and objectives of language learning as well as to cope with difficulties, increase and exploit strengths and overcome weaknesses effectively and efficiently. Action means any physical or mental operation (individual or sequenced) that involves an activity, movement or change performed by an agent acting voluntarily.

\section{Other inherent aspects of learning strategies}

I have already stated the two essential attributes of strategies; however, it is also worth mentioning briefly other secondary inherent features of this concept.

Main purpose. Language learning strategies (LLS) play the role of its original Indo-European etymon: expanding the development of communicative competence in an optimal way.

They involve more than just cognitive processes. LLS are not only exclusively restricted to cognitive mental functions, but they also include motor and articulatory actions, behavior and activities of affective control. 
They are not always observable. Mental operations cannot be accessed through external exploration although in some cases there is the possibility that the subject expresses his/her activities, such as in verbal reports. Furthermore, there is another problem for researchers using personal observation since there are numerous strategies used outside the field of the formal instruction and of the observer's eye.

They are automatable. Training in LLS may be necessary to help learners become more conscious about the strategies they use and evaluate their benefits. However, the practice and use of these strategies may lead to automatization (Fernández, 2004; Oxford, 1990), which means less cognitive resources required. Griffiths (2013) added that since they are conscious activities, strategies can be performed in a continuum between two extremes: automatically (more likely for experienced learners) and deliberately (more likely for novice learners).

Associated variables. LLS could be associated to a large number of variables and this has been a prolific subject of study in this area. Some of the variables Griffiths (2013) mentioned from several studies were motivation, nationality, sex, learning style, identity, personality, etc.

Difficulties, problems and strengths. LLS include those actions that a learner does to cope with difficulties, increase and exploit strengths and overcome weaknesses in the process of language learning.

Objectives and goals. The presence of language learning objectives and goals is a necessary condition (but not enough) for the existence of a strategy.

Intentionality. A strategic action is neither random nor based on erratic or random behavior; instead it is performed in an intentional and deliberate way. Instituto Cervantes (2006) distinguished between procedures and strategies by establishing that the first can be used mechanically without a learning intention, whereas in the case of learning strategies, there is a degree of consciousness and intentionality and they are intended to achieve learning objectives. Nevertheless, I consider that although there are some actions without the intention of learning, there is no certainty that learning does not take place. Moreover, even when there is an intention of learning, it does not mean that learning takes place. Furthermore, the reflective condition about the mere performance of an action, that is, having full consciousness of the performance act, does not make it strategic. What is important is the reflection on the reason for such action and no other, and the benefits or usefulness it provides.

They can be taught and learned. LLS can be taught as shown in different studies (Graham \& Macaro, 2008; Gunning \& Oxford, 2014; Vandergrift \& Tafaghodtari, 2010; McDonough, 1999). Instruction helps to become more conscious of the use of strategies and to employ them appropriately. This preparedness is more effective when students learn why and when certain strategies are important, how to use them and transfer them to other situations; even the fact that students reflect upon what strategies they use could help in their present and future learning.

\section{Discussion}

In order to be able to operationalize a concept, in other words, to translate it from theoretical language to the empirical field, the first step is to define its properties or attributes and transform them into variables. In relation to this, Dörnyei expressed:

\section{In the absence of a tight definition, it is unclear what different researchers mean by the term language learning strategy and the actual language learning measures presented in the various studies tend not to have sufficient psychometric properties (Dörnyei 2005, p. 188).}

In light of the problem presented about the low specificity of the term strategy in education and the controversies about its characteristics and limits, another perspective that may, at least, try to give more concrete and operationalizable answers is needed. In this article, I define the concept of strategy in terms of its two main attributes, effectiveness and efficiency. This proposal differs from those paradigms that served as the basis until 
now to face the problem of 'fuzziness'. In the following lines I present the most relevant implications.

First, the difference between strategic and non-strategic is now established. This is, if the optimum conditions of effectiveness and efficiency in an action are met, it is a strategy; otherwise, it is only an activity. Second, any action aimed at a learning goal can be strategic or not, depending on the person and the circumstances. It is not possible to say with absolute certainty in advance that a particular activity will be strategic for everybody since each personality is a unique and non-transferable construct of each person. In other words, each person is unique and identical to him/herself in their psyche, upon which learning is inherently dependent. Hence, I consider that the strategic dimension in learning is subjective; it is an appreciation that depends on each person after performing a certain action to achieve an objective or a goal. Being $U$ the universe of possible actions, a learner chooses and uses a subset $A$ of this universe so as to attain goals and objectives of learning a language, cope with difficulties, increase and exploit strengths and overcome weaknesses. In subset $A$, there are elements which would be more effective and efficient (useful) than others in different circumstances. We may label these actions as strategies and classify them into another subset $S$. Strategies take place in certain circumstances and it may be interesting to know when, where, how frequently, etc. Studies about these circumstantial questions are common. However, they may be ignoring the effectiveness and efficiency, which are the most important aspects, since they determine the real impact of any action. Furthermore, the label of strategy cannot be assigned to a certain action without having previously using it and evaluating it. Unless there is a significant probabilistic and empirical trend towards considering certain activities as strategic by a determined population, I recommend referring to them using the term strategy and even then, with certain reservations, awareness and precaution of what could be non-strategic for some people. Learners and teachers could take advantage from the experience of other learners and take into consideration the most common strategies.

The main challenge for this approach to LLS is the operationalization. To confirm with absolute certainty whether an activity, in a determined context and with a defined objective, is strategic or not, a huge experimental study should be carried out in which countless tasks of the universe of possibilities under the same conditions should be done and then results should be compared to see which are more efficient and effective. This undertaking is beyond any rational possibility of execution, given our mortal nature and the resource limitation for such a purpose. The problem gets even more complex if learning is thought to happen at every moment and not only in a directed teaching environment. On the basis of this, I suggest resorting to the metacognition of the individuals, which is probably not the most precise option, but the most feasible. Since learning strategies are conscious or potentially conscious mental actions, it is highly probable that the subjects are aware of the intentions, know the tasks to be executed (and their requirements), and above all, they may evaluate the whole process. The resulting usefulness is also perceived and registered in the learner's memory, as important information to be considered in future similar situations.

Lastly, with regard to future studies, exploring relationships between language learning strategies and factors of different nature would help to understand the complexity in L2 learning. In this sense, Gavriilidou and Petrogiannis (2016), Sadati and Simin (2015), Platsidou and Sipitanou (2014) identified relationships between the frequency of use of language learning strategies and different variables such as grade level, gender and language proficiency. Similar methodologies could be applied to have a broader vision on learning strategies, operationalized in terms of usefulness.

In conclusion, with the proposal presented in this article I intend to contribute to a more complete understanding about learning strategies and the ways to optimize language learning. It is too early to ensure the impacts of this perspective and a lot of work needs to be done in this field.

\section{References}

Bialystok, E. (1984). Strategies in interlanguage learning and performance. In A. Davies, C. Criper, \& A. P. R. Howatt (Eds.), Interlanguage (pp. 37-48). Edinburgh: Edinburgh University Press. 
Di Carlo, S.

Bialystok, E. (1990). Communication strategies. Oxford: Blackwell.

Braunstein, N. A., Pasternac, M., \& Benedito, G. (2002). Psychology: Ideology and science [In Spanish]. Mexico: Siglo XXI.

Chamot, A. U. (2001). The role of learning strategies in second language acquisition. In M. Breen (Ed.), Learner contributions to language learning: New directions in research (pp. 25-43). Harlow: Longman.

Cohen, A. D. (1996). Second language learning and use strategies: Clarifying the issues. Retrieved from http://carla.umn.edu/strategies/resources/SBIclarify.pdf

Cohen, A. D. (1998). Strategies in learning and using a second language. New York: Longman.

Cohen, A. D. (2015, October 16-17). Moving from theory to practice: A closer look at language learner strategies. Paper presented at the meeting of the Alpen-Adria Universitait, in Klagenfurt, Austria.

Cohen, A. D., \& Griffiths, C. (2015). Revisiting LLS research 40 years later. TESOL Quarterly, 49(2), 414-429. http://dx.doi.org/10.1002/tesq.225

Council of Europe. (2002). Common European framework of reference for languages: Learning, teaching, assessment. Strasbourg: Cambridge University Press.

Díaz Barriga, F., \& Hernández Rojas, G. (2002). Teaching strategies for meaningful learning. A constructivist interpretation [In Spanish]. Mexico: McGraw-Hill.

Dörnyei, Z. (2003). Questionnaires in second language research: Construction, administration, and processing. New Jersey: Lawrence Erlbaum Associates.

Dörnyei, Z. (2005). The Psychology of the language learner. Individual differences in second language acquisition. London: Lawrence Erlbaum Associates.

Dörnyei, Z., \& Scott, M. L. (1997). Communication strategies in a second language: Definitions and taxonomies. Language Learning, 47(1), 173-210. http://dx.doi.org/10.1111/0023-8333.51997005

Færch, C., \& Kasper, G. (1983). Strategies in interlanguage communication. New York: Longman.

Fernández López, S. (2004). Learning strategies [In Spanish]. In J. Sánchez Lobato and I. Santos Gargallo (Eds.), Handbook for teacher training. Teaching Spanish as a second language and foreign language [In Spanish] (pp. 411-432). Madrid: SGEL.

Ferreras Remesal, A. (2008). Learning strategies. Construction and validation of a questionnaire-scale [In Spanish]. Doctoral dissertation, Universitat de Valencia, Valencia, Spain.

Gavriilidou, Z., \& Petrogiannis, K. (2016). Language learning strategy use of English FL learners in Greek schools: The role of school type and educational level. International Journal of Research Studies in Language Learning, 5(4), 67-81. http://dx.doi.org/10.5861/ijrs1l.2016.1346

Graham, S., \& Macaro, E. (2008). Strategy instruction in listening for lower-intermediate learners of French. Language Learning, 58(4), 747-783. http://dx.doi.org/10.1111/j.1467-9922.2008.00478.x

Griffiths, C. (2013). The strategy factor in successful language learning. Bristol: Multilingual Matters.

Gunning, P., \& Oxford, R. (2014). Children's learning strategy use and the effects of strategy instruction on success in learning ESL in Canada. System, 43, 82-100. http://dx.doi.org/10.1016/j.system.2013.12.012

Instituto Cervantes. (2006). Instituto Cervantes curriculum plan. Reference levels for Spanish [In Spanish]. Madrid: Biblioteca Nueva.

Larsen-Freeman, D. (2001). Individual cognitive/affective learner contributions and differential success in second language acquisition. In M. Breen (Ed.), Learner Contributions to Language Learning (pp. 12-23). Harlow: Longman.

Macaro, E. (2006). Strategies for language learning and for language use: Revising the theoretical framework. The Modern Language Journal, 90(3), 320-337. http://dx.doi.org/10.1111/j.1540-4781.2006.00425.x

McDonough, S. H. (1999). Learner strategies. Language Teaching, 32(1), 1-18. http://dx.doi.org/10.1017/S0261444800013574

McLaughlin, B. (1990). "Conscious" versus "Unconscious" Learning. TESOL Quarterly, 24(4), 617-634. http://dx.doi.org/10.2307/3587111

Nisbet, J., \& Shucksmith, J. (1986). Learning strategies. London: Taylor \& Francis/Routledge.

O'Malley, J. M., \& Chamot, A. U. (1990). Learning strategies in second language. Cambridge: Cambridge University Press. http://dx.doi.org/10.1017/CBO9781139524490 
Oxford, R. (1990). Language learning strategies: what every teacher should know. New York: Newbury House.

Oxford, R. (1993). Language learning strategies in a nutshell: Update and ESL suggestions. TESOL Journal, 2(2), 18-22.

Oxford, R. (2013). Teaching and researching language learning strategies. New York: Routledge.

Oxford, R., \& Cohen, A. (1992). Language learning strategies: Crucial issues of concept and classification. Applied Language Learning, 3, 1-35.

Pastor, B., \& Roberts, A. E. (1996). Indo-European etymological dictionary of the Spanish language [In Spanish]. Madrid: Grupo Anaya.

Platsidou, M., \& Sipitanou, A. A. (2014). Exploring relationships with grade level, gender and language proficiency in the foreign language learning strategy use of children and early adolescents. International Journal of Research Studies in Language Learning, 4(1), 83-96.

Reid, J. M. (1998). Understanding learning styles in the second language classroom. Upper Saddle River, NJ: Prentice Hall Regents.

Rubin, J. (1975). What the "good language learner" can teach us. TESOL Quarterly, 9(1), 41-51. http://dx.doi.org/10.2307/3586011

Sadati, S., \& Simin, S. (2015). The relationship between metacognitive and self-regulated learning strategies with learners' L2 learning achievement. International Journal of Research Studies in Language Learning, 5(2), 97-106.

Schmidt, R. (1994). Deconstructing consciousness in search of useful definitions for applied linguistics. In J. H. Hulstijn \& R. Schmidt (Eds.), Consciousness in second language learning (pp. 11-26). Amsterdam: John Benjamins.

Vandergrift, L., \& Tafaghodtari, M. H. (2010). Teaching L2 learners how to listen does make a difference: An empirical study. Language Learning, 60(2), 470-497. http://dx.doi.org/10.1111/j.1467-9922.2009.00559.x

Wenden, A. (1991). Learner strategies for learner autonomy. London: Prentice Hall. 
Di Carlo, S. 